\title{
A BIBLIOTECA PÚBLICA DE BELO HORIZONTE: O LEGADO CULTURAL DE UMA SOCIEDADE LITERÁRIA
}

\section{LA BIBLIOTECA PÚBLICA DE BELO HORIZONTE: EL LEGADO CULTURAL DE UNA SOCIEDAD LITERÁRIA}

\author{
Aline Pinheiro Brettas - apb27@hotmail.com \\ Doutoranda em Ciência da Informação pela Universidade Federal de Minas \\ Gerais, UFMG.
}

\begin{abstract}
Resumo
Apresenta reconstrução histórica da Biblioteca Pública de Belo Horizonte, desde sua fundação até a extinção. Analisa a contribuição da Biblioteca para a constituição da memória e da identidade da cidade. A fundamentação teórica baseia-se em estudos sobre a biblioteca pública e em leituras sobre a história de Belo Horizonte e do Brasil. A metodologia tem como eixo a análise documental, complementada por consulta a fontes teóricas. Os documentos analisados são de origem oficial, tais como relatórios e legislação; e de origem não-oficial, como os artigos de jornais. A contraposição documental permitiu uma abordagem dialética. A história da Biblioteca foi dividida em três etapas: criação, institucionalização e extinção da instituição. A contribuição da Biblioteca Pública de Belo Horizonte para a constituição da memória e da identidade da cidade foi comprovada por meio do acervo e dos serviços oferecidos pela instituição.
\end{abstract}

\section{Palavras-chave}

Bibliotecas públicas. Identidade cultural. Memória.

\section{INTRODUÇÃO}

Esse artigo tem por objetivo apresentar um estudo sobre a história da Biblioteca Pública de Belo Horizonte, mostrando a criação da instituição e a sua passagem por três posteriores fases distintas, marcadas por mudanças administrativas que determinaram o espaço que a instituição ocupou na cidade:

- primeira fase ou fase inicial (os primeiros trinta anos): a Biblioteca continha um volume de acervo e um quadro de funcionário reduzidos;

- segunda fase ou fase intermediária (entre 1930 e 1937): período de expansão, quando tinha regulamento próprio e não era subordinada a nenhum departamento da Prefeitura; 
terceira fase ou fase final (entre 1937 e 1963): caracterizada por um declínio gradual, quando a instituição tornou-se subordinada a diversos departamentos da Prefeitura e deixou de ter o seu regulamento.

Esclarecemos que, ao longo dessas etapas, delineadas por uma análise histórica, a Biblioteca desenvolveu a organização e disponibilização do acervo de acordo com influências política e culturais. A delimitação das três fases se deu, neste caso, através da consulta a documentos oficiais, originários da Administração Pública Municipal, como os relatórios que os prefeitos encaminhavam ao Presidente do Estado de Minas Gerais. Devemos ressaltar que os chefes do Poder Executivo Municipal eram nomeados pelos presidentes do Estado até 1931 e, a partir de então, pelos governadores do Estado. Situação essa que se encerrou em 1947; desde então, os prefeitos, devido à autonomia obtida perante o Governo Estadual, encaminham os relatórios à Câmara de Vereadores. A legislação municipal também foi um material crucial para localizar a situação da Biblioteca perante a organização administrativa da Prefeitura de Belo Horizonte.

\section{A CRIAÇÃO}

Em 1894, o Brasil tinha acabado de se tornar uma república.

O país foi atingido por um fervor ideológico, sendo que os conceitos de democracia, federação e educação constituíam categorias inseparáveis apontando a redenção do país (BEISIEGEL, 1997).

Minas Gerais, por sua vez, havia se consolidado como unidade política, quando a elite passou a se preocupar com problemas internos, dentre eles, a mudança da capital do estado. Belo Horizonte fora idealizada e criada dentro desse contexto. Em 1893, teve início a construção da primeira cidade planejada no país, quando o Presidente do Estado contratou uma Comissão Construtora sob a direção do engenheiro-chefe Aarão Reis - encarregada de planejar e executar a construção da cidade. A nova capital fora inaugurada em 12 de dezembro de 1897.

A Biblioteca Pública de Belo Horizonte foi instituída no espírito que orientou a construção de Belo Horizonte, precedendo a inauguração da cidade. Alguns membros da Comissão - os engenheiros Fábio Nunes Leal, Samuel Gomes Pereira, Américo de Macedo e José de Magalhães - deliberaram fundar a "Sociedade Literaria Bello Horizonte", cuja finalidade seria a organização de uma biblioteca e um museu. Em 27 de agosto de 1894, os engenheiros supracitados se reuniram com Aarão Reis para apresentar um ofício que expunha os planos da fundação e as bases da instituição.

É interessante observar que os membros da Comissão consideravam a Biblioteca como o repositório das "glórias do futuro", ou seja, da cultura que iria se formar na cidade. No entanto, eles propuseram que a coleção inicial fosse formada com materiais informacionais ligados à sua atividade profissional, o que significa então que o acervo seria voltado para um público específico. 
A filosofia que norteou a criação da Biblioteca foi inspirada em modelos americanos. Nos Estados Unidos, em fins do século XIX, a educação se tornou base fundamental para a democracia. Nesse contexto, a biblioteca pública era fervorosamente defendida e promovida, por ser considerada um meio capaz de difundir o conhecimento, tratando a todos como iguais e colocando os recursos da nação ao alcance de todos.

Aarão Reis foi convidado a ser presidente honorário da instituição, e lhe foi solicitada uma edificação adequada. Ele aceitou o convite e cedeu imediatamente uma casa velha existente no Largo da Matriz, onde a biblioteca funcionou até depois de inaugurada a nova capital. O acervo inicial da instituição compôs-se de livros doados pelos próprios membros da Comissão.

Há também o registro de recebimento de revistas científicas, por parte dos membros da Comissão, Samuel Pereira, José de Magalhães e Fábio Nunes Leal, em 25 de outubro de 1894. Foram recebidos títulos de periódicos técnicos e científicos, sobre arquitetura, construção, engenharia e aspectos naturais. A maioria deles, $58 \%$, era de origem francesa, $25 \%$ eram escritos em idioma inglês, e $12,5 \%$ em idioma alemão, e apenas um periódico estava escrito em idioma português. O que mostra a propensão da Comissão, especialmente por parte de seu engenheiro-chefe, em receber os "ecos de modernização" do continente europeu, o que representou uma tendência naquele período: a cultura brasileira estava se inspirando no modelo cultural europeu, principalmente no francês. Além disso, o acervo era especializado, cujos assuntos eram apropriados aos engenheiros. À Biblioteca foi dada a denominação de "Sociedade Literária de Belo Horizonte".

Em 10 de janeiro de 1897, a Sociedade Literária aprovava os seus estatutos, o que indicava que ela estava se institucionalizando, adotando normas que deveriam apontar cargos, funções, condições para consulta, etc. Cabe enfatizar aqui que não foi possível comprovarmos esta informação por não termos acesso ao estatuto.

Quando a nova capital fora inaugurada e os trabalhos da Comissão Construtora foram encerrados, o acervo da Biblioteca, que contava com cerca de 4.000 volumes, foi doado à Prefeitura.

Segundo Barreto (s.d, p. 1) ${ }^{1}$, a Biblioteca estava instalada na Rua da Bahia, no Edifício da Câmara, desde 1899.

Belo Horizonte foi concebida e construída dentro de um ideal republicanista, de acordo com o novo sistema político, que nascia no Brasil e que era copiado dos Estados Unidos, uma vez que este país era considerado o modelo de república federativa. Esse sistema representava também a supressão da tradição colonial e um "salto para a modernidade"; além disso, apresentava um ideal positivista, que associava a república ao projeto de progresso e civilização e que era simbolizado pela ordem, implantada por meio de leis e regras que deveriam orientar a conduta da população. A educação, democracia e federação estariam diretamente ligadas à redenção do país. A Sociedade Literária de Belo Horizonte foi criada na cidade para atender àquele projeto, seguindo as idéias e

1 Essa informação foi retirada de um documento arquivístico que não apresenta dados tipográficos. 
moldes europeus e americanos. No entanto, apesar dessas influências que permeavam a mentalidade dos criadores da Biblioteca, esta instituição possivelmente não cumpriu o objetivo de educar os habitantes de Belo Horizonte, uma vez que o acervo era inicialmente direcionado a um público específico, composto por engenheiros e intelectuais.

\section{DA INSTITUCIONALIZAÇÃO MUNICIPAL ATÉ A EXTINÇÃO}

A Biblioteca, depois de doada à Prefeitura, ficou situada em um prédio na Rua da Bahia. O edifício era provisório, mas não havia recursos para instalar a instituição em um local próprio; e inadequado, pois não satisfazia às conveniências do serviço. Em 1904, a Biblioteca foi transferida para o salão térreo do edifício que na época abrigava o Senado. A nova edificação, no entanto, também era imprópria. Em 6 de setembro de 1914, foi inaugurado oficialmente 0 palácio do Conselho Deliberativo, situado na esquina da Rua da Bahia com a Avenida Paraopeba (atual Avenida Augusto de Lima).

Nesse mesmo dia, a Biblioteca foi também transferida para esse local, onde funcionou até 1963.

A instituição recebia doações de pessoas importantes no cenário político e intelectual de Belo Horizonte, tais como do Ministro das Relações Exteriores Doutor Olyntho de Magalhães (BELLO HORIZONTE, 1902), do Almirante Arthur de Jaceguay e do Doutor Olyntho Meirelles (BELLO HORIZONTE, 1903). Como a Biblioteca nem sempre conseguia através da Prefeitura os recursos necessários para a aquisição de obras, ela contava com o apoio de particulares.

Uma nova organização do acervo começou a ser implantada na Biblioteca em 1925. Os livros compunham várias áreas do conhecimento, como literatura, história, química, física, filosofia, matemática, geografia, agronomia, ciências, botânica, direito. Nesse período, a Biblioteca recebia muitos jornais, periódicos e diários legislativos.

Foi adotado o sistema de classificação decimal, criado por Melvin Dewey, um teórico da Biblioteconomia que defendeu, nas três últimas décadas do século XIX, a idéia de que a biblioteca pública deveria ser um meio de difundir a educação. Esse sistema foi elaborado para atender a intensa atividade intelectual que começava a ser desenvolvida.

O decreto municipal $n^{\circ} 16$, de 12 de maio de 1927, que regulamentava os serviços da Prefeitura, determinou que a preservação do acervo também era uma atribuição do bibliotecário (BELO HORIZONTE, 1992-1994a). Desde então, os livros e periódicos passaram a ser encadernados.

A fase inicial da Biblioteca coincidiu com o período que no Brasil é chamado República Velha ou Primeira República. O processo político, na década de 1920, foi caracterizado pela maior visibilidade da presença da classe média urbana na cena política, que deveria visar a transformação da República oligárquica em República liberal. Essa década também marcou o término da construção de Belo Horizonte. Naquele momento, a grande preocupação era o crescimento da capital de Minas Gerais, que até então havia se estagnado. Acompanhando o crescimento dos setores urbanos, a atuação da biblioteca 
pública em relação à educação expandiu-se, já que o público se tornava cada vez maior e mais urbanizado. Era essencial tornar a biblioteca conhecida por todos, e novos meios de atrair leitores foram criados.

A Biblioteca, ao se inserir naquele contexto, também proporcionou a publicação de notas e artigos de jornal, apresentando informações sobre a freqüência e o acervo recebido. Esse acervo, além de obras em idioma português, comportava número significativo de obras em idiomas estrangeiros, principalmente o francês, além de clássicos da literatura nacional e internacional. O público parecia se interessar por esse acervo, como podemos verificar nos seguintes relatórios:

O melhor testemunho de que as reformas introduzidas nesse departamento da Prefeitura satisfazem às suas exigencias está no augmento sempre crescente de visitantes. Em contraposição ao n. de 1875 que visitaram o salão de leitura durante o anno de 19031904, ponho o de 5.975 o das que o freqüentaram no anno de 1904-1905 (BELLO HORIZONTE, 1906, p. 12).

... sendo a única Biblioteca Publica na Capital, grandes beneficios vem prestando á população, principalmente á classe de estudantes; a sua freqüência, de 31 de Agosto de 1922 a egual data de 1923, attingiu a 20.242 pessoas, que, além da leitura de jornaes e revistas, consultaram diversas obras de sciencias e artes, no total geral de 20.398 exemplares (BELLO HORIZONTE, 1923, p. 32-33).

Podemos perceber na primeira citação que o número de consulentes quase triplicou de um ano para o outro. A segunda citação, por sua vez, mostra que havia uma classe mais beneficiada, composta pelos estudantes, além de apresentar o número de pessoas que freqüentaram a Biblioteca, e qual o tipo de obra procurado pelo público, entre os anos de 1922 e 1923. Isso significa que o acervo era bastante apropriado aos estudantes que procuravam a Biblioteca para encontrar as informações necessárias às suas leituras e pesquisas escolares. Nesse período, a educação do povo era considerada um meio de conquistar o sentimento de identidade nacional, além de surgirem no Brasil as primeiras grandes universidades - dentre elas, a de Minas Gerais, em 1927. A Biblioteca se inseriu naquele contexto, sendo que grande parte do seu público era composta por estudantes primários.

Na fase intermediária, que ocorreu entre 1930 e 1937, o decreto municipal no 64 - de 7 de março de 1930 - regulamentou a Biblioteca, tornando-a subordinada diretamente à Prefeitura e com mais autonomia (BELO HORIZONTE, 1992-1994c). Esta norma apresentou o quadro de funcionários, que deveria constar de um bibliotecário, um ajudante, três encarregados, seis fiscais da leitura e dois porteiros-serventes. Foram regulamentadas as competências de todos eles, no que tange à administração geral da instituição, atendimento, conservação e organização do acervo. Mas, como esses funcionários deveriam proceder? Quais deveriam ser suas capacitações e habilidades? A resposta nos é apresentada por Menegale, um respeitado intelectual da cidade e bibliotecário da instituição por cerca de quinze anos, em seu relatório apresentado ao Prefeito Luiz Penna: 
Casa de educação, a biblioteca requer pessoal preparado e predisposto e não alfabetos e leigos, pelo menos para determinados encargos.

Em primeiro lugar, o funcionário deve ter certas qualidades naturais, como a afabildade do trato e alguma agilidade de espírito, para cativar e orientar o leitor. Uma boa vontade excepcional vem a suprir, em parte, tais predicados que, na prática, nem sempre se podem exigir. Sobretudo o bibliotecário, desenvolve uma atividade verdadeiramente magisterial, se se compenetra da finalidade do estabelecimento e da nobreza do seu cargo ... convem deferir-lhe no cargo toda a autonomia ... os resultados mais satisfatórios se obtêm quando esse funcionário gosa da prerrogativa de nomear os seus empregados, escolher os livros, comprar o material necessário, fazer os regulamentos, determinar o método que se há de seguir na catalogação, classificação e circulação; em suma, quando governa 0 estabelecimento (MENEGALE, 1932, 26-28).

Menegale (1932) mostra a necessidade, por parte do bibliotecário, da elaboração e concepção de métodos, reformas e melhorias de serviço. $O$ bibliotecário deveria também manter um contato com os funcionários da instituição, para colher impressões pessoais sobre a freqüência, as predileções, tendências e exigências dos usuários. Para tal profissão, havia necessidade de uma educação apropriada, já que ela estava se tornando bastante especializada.

Ainda em 1930, com o decreto municipal ํㅜ 63, de 06 de março, o Prefeito autorizara a criação de uma seção denominada "Biblioteca de Autores Mineiros", destinada a recolher as produções e a documentação da Literatura, História e Geografia de Minas Gerais (BELO HORIZONTE, 1992-1994b). Interessante apontar que, nesse período, já se cogitava a criação de uma biblioteca pública para Minas Gerais, onde seriam reunidos todos os acervos sobre o estado, encontrados nas bibliotecas públicas municipais.

O bibliotecário J. Guimarães Menegale realizou uma classificação inspirada no modelo da Biblioteca do Congresso, em Washington, tendo em vista as condições da Biblioteca Municipal, sua natureza e desenvolvimento. O acervo abrangia diversos assuntos, e podia ser acessado por um público diferenciado. Em 1936, pelo novo regulamento dado à instituição pelo decreto municipal no 67 de 11 de fevereiro, a instituição deveria manter uma seção "Braille", com livros dedicados aos deficientes visuais (BELO HORIZONTE, 2004).

Em 1935, a Biblioteca contava com enciclopédias, dicionários (BOLETIM, 1935, p. 32-35) e coleções sobre história, lógica, metafísica, introdução à filosofia, epistemologia e teoria do conhecimento, cosmologia, ontologia, psicologia, ciências ocultas, ética, religiões e mitologia. Essas obras poderiam ser encontradas no idioma português e em idiomas estrangeiros, dentre eles o inglês e, principalmente, o francês (BOLETIM, 1935, p. 79-82). Podemos constar que a instituição continuava a primar pela diversidade de assuntos e de idiomas que deveriam ser encontrados em seu acervo.

Quanto à preservação do acervo, o decreto municipal nำ 64 de 7 de março de 1930 determinou que ela continuaria sendo atribuição do bibliotecário. No entanto, foi previsto que um ajudante deveria auxiliá-lo (BELO HORIZONTE, 
1992-1994c). O encarregado, por sua vez, deveria fiscalizar a consulta do público, para evitar extravios e depredações das obras. Já o fiscal de leitura era responsável por impedir a infração de qualquer prescrição do regulamento, no que se referia à preservação das obras, objetos e mobiliário por parte dos consulentes. Em 1936, o novo regulamento dado à Biblioteca pelo decreto municipal n 67 de 11 de fevereiro determinou que a preservação do acervo, através de sua constante limpeza e tratamento, bem como o asseio, segurança e conservação do edifício, deveriam ser de responsabilidade do serviço de conservação (BELO HORIZONTE, 2004).

O movimento fascista italiano que se desenrolava naquele período influenciou o campo político no Brasil, com o surgimento do Estado Novo, fazendo com que a corrente autoritária ganhasse espaço na cultura política do país. No campo cultural, os intelectuais passaram a ser eleitos pelo Estado brasileiro como intermediários entre ele e a sociedade. As elites políticas consolidavam em seus atos administrativos e políticos as idéias que as elites intelectuais formavam. Nesse sentido, qualquer manifestação de pensamento contrário ao Estado era considerada subversiva e maliciosa. Em 4 de abril de 1935, Getúlio Vargas editou a Lei $n^{\circ} 38$, que definia crimes contra a ordem política e social (BRASIL, 2004).

Segundo o parágrafo único do artigo 26 desta lei, todas aquelas publicações deveriam ser apreendidas. Isso comprova já uma preocupação do Estado Varguista em controlar algum tipo de influência ideológica contrária às suas normas. Segundo Motta (2003), houve uma intervenção estatal até mesmo no desenvolvimento do acervo literário no Brasil, tanto os comercializados em livrarias, quanto os disponibilizados nas bibliotecas.

Em Belo Horizonte, a administração pública municipal adotou uma política repressiva, inclusive na constituição do acervo da Biblioteca Pública. O próprio Menegale (1932, p.16) foi influenciado por essa ideologia autoritária, como podemos perceber no seu relatório:

... o Estado que só proporciona a instrução rudimentar e não cuida de completar, no individuo, as noções da vida e da natureza, realiza obra ineficiente, e não só ineficiente, senão tambem insensata e perigosa. Ler não é só arma de cultura, é arma, tambem, de perversão. Assim, quando a literatura nociva se tornou, pelos seus preços, tão vulgar e accessivel, impõe-se facilitar a todo transe a boa leitura, capaz de, contrapesando a outra, forrar o individuo e, por consequencia, a massa popular á corrupção moral e social.

Em 21 de outubro de 1937, o prefeito Otacílio Negrão de Lima, por meio do decreto municipal $\mathrm{n}^{-}$135, tomou uma medida bastante coercitiva, como podemos observar a seguir:

Considerando que o país atravessa uma fase de excepcional gravidade, em virtude de indisfarçáveis ameaças ao regimen e às instituições sociais; Considerando que todas as fôrças morais e materiais foram convocadas para prevenir a possibilidade de surtos extremistas;

Considerando que é indeclinável dever das autoridades colaborar com o Governo da República nas medidas de defesa da ordem política e sociais, não somente pela reação a ataques diretos 
como a tudo quanto possa inspiral-os por sugestão ou propaganda;

Considerando, finalmente, que a Biblioteca Pública é, pelos próprios termos de sua organização, um estabelecimento de educação popular e, como tal, deve concorrer para avivar e robustecer no espírito público a fé e confiança nas instituições vigentes;

resolve nomear uma comissão composta dos doutores Mário Mendes Campos, Francisco de Assis Gomes e Oscar Mendes, para, juntamente com o Inspetor de Educação, Assistência e Turismo, proceder a uma verificação das obras existentes na Biblioteca Pública, eliminando aquelas que, pela sua ideologia comunista, ou, de qualquer forma, contrárias ao regimen, se tenham tornado prejudiciais a educação do povo (BELO HORIZONTE, 1938, p. $45-46$ ).

Alguns meses depois, após a publicação desse decreto, o trabalho determinado por ele foi concretizado. Segundo Motta (2003), a comissão recolheu 74 obras, dividindo-as em três categorias:

- comunistas ou "communizantes" (21);

- de consulta reservada (16);

- inconvenientes (37).

Nos 21 livros ditos comunistas predominava a temática política ${ }^{2}$. As outras obras não foram apresentadas pela imprensa, o que tornou impossível conhecer os outros títulos considerados inadequados, ou seja, as obras que foram classificadas como inconvenientes ou de consulta reservada. A ditadura varguista, nesse sentido, gerou um intenso controle da informação na Biblioteca Pública de Belo Horizonte, pois ao eliminar os livros comunistas ou "comunizantes", a instituição estava impedindo que a população tivesse acesso às idéias que neles estavam registradas.

No entanto, houve uma maior preocupação da Biblioteca com a sua popularização. Ela passou a atender alguns grupos da sociedade que necessitavam de uma atenção especial: as crianças, os deficientes visuais, os presidiários. Nessa fase, a instituição também começou a se preocupar com a realização de atividades de difusão cultural. O artigo 35 do decreto no 64 determinou que na Biblioteca haveria uma sala de conferências, que poderiam se realizar mediante a permissão do bibliotecário ou este as promoveria, escolhendo os assuntos e convidando as pessoas que delas teriam que se encarregar (BELO HORIZONTE, 1992-1994c). No entanto, o decreto ressaltou que "assuntos facciosos" não poderiam ser apresentados. O novo regulamento da Biblioteca

\footnotetext{
${ }^{2}$ A Educação na Russia Sovietica, Fridman; Em marcha para o socialismo, Staline; Destin d'uma Revolution, Victor Serge; Anarchismo, Communismo, Socialismo, Nicanor Nascimento; A vida sexual na Russia Sovietica, H. Fouillé; Staline, Barbusse; A medicina na Russia, dr. Lelio O. Zeno; U.R.S.S. um novo mundo, Caio Prado Junior; Introducção á Sciência do Direito, Hermes Lima; Ponta de Rua, Frão Martins; Safra, Abguar Bastos; Terra de Icamiaba, Abguar Bastos; Certos caminhos do Mundo, Abguar Bastos; Problemas do nosso tempo, Hermes Lima; As bases do separatismo, Vanderlei; O problema feminino e o divorcio, Augusto Cesar; Christianismo, Cattolicismo e Democrazia, A. Piccarolo; Cimento, Fedor Gladkov; Russia, Mauricio de Medeiros; O Plano quinquenal, G. Grinko; Communismo, Lenine.
} 
dado pelo decreto no 67, em 1936, no artigo 9ำ, determinou que o bibliotecário deveria distribuir por outras bibliotecas públicas as duplicatas das obras existentes, bem como fazer as permutas que poderiam ser vantajosas (BELO HORIZONTE, 2004). Além disso, o bibliotecário deveria dirigir o "Boletim Bibliographico" - publicado em quatro edições no ano de 1935 - e que apresentava várias informações sobre a instituição, tais como freqüência, acervo, regras para consulta ao acervo, dentre outras. Além disso, encontravam-se notas sobre a cidade e artigos de intelectuais belo-horizontinos.

$\mathrm{Na}$ fase final, entre 1937 e 1963, a Prefeitura havia se tornado uma administração complexa, com diversos departamentos e serviços. Com isso, a Biblioteca passou a ser subordinada ao Departamento de Cultura e o seu quadro de funcionários tornou-se mais diversificado, tendo em vista a complexidade do serviço executado. Tal quadro constou de: um diretor; um bibliotecário; um catalogador-chefe; um ecônomo; um catalogador auxiliar de 1ạ; um catalogador auxiliar de $2^{\mathrm{a}}$; um auxiliar datilógrafo; um oficial de consulta de 1aㅜ um oficial de consulta de $2^{\underline{a}}$; três oficiais de consulta de $3^{\mathrm{a}}$; dois oficiais de consulta de $4^{\mathrm{a}}$ e dois porteiros-serventes ${ }^{3}$.

Um novo sistema de classificação foi introduzido nas bibliotecas: a classificação decimal universal, que inspirou a Biblioteca Pública a reelaborar o seu catálogo bibliográfico, para incluir números de chamada segundo aquele sistema. O trabalho foi realizado pelo funcionário Fernandes Viana, com a cooperação dos funcionários Antônio Fonseca Pimentel e Geraldo Majela de Andrade Câmara, e sua publicação foi autorizada pelo Prefeito Juscelino Kubitschek.

Em 1951, foi restabelecida a assinatura de jornais destinados ao público. No entanto, o patrimônio da Biblioteca crescia aquém do necessário, conforme o relatório de 1952:

A dotação consignada no orçamento do último exercício, destinada à aquisição de novos volumes, não permitiu a realização de um plano de longa envergadura para que 0 patrimônio de nossa principal biblioteca pudesse se enriquecer. Não obstante, foram adquiridas algumas obras de valor, que passaram a enriquecer as estantes franqueadas à consulta da população da Capital (BELO HORIZONTE, 1953, p. 105).

A partir de então, o acervo tornou-se desatualizado. Em 1952, apesar de ter sido despendida uma verba para a aquisição de novas obras e assinaturas de revistas e jornais, ele não se expandiu. Podemos observar a grande mudança ocorrida em relação às obras adquiridas, sendo que naquele ano foram incorporadas ao acervo obras literárias e sobre belas artes, filosofia, filologia, história, geografia, ciências sociais, puras e aplicadas. O idioma português passou a ser predominante, sendo que os outros idiomas, tais como o francês, o inglês, o italiano e o alemão continuaram a fazer parte da coleção, mas em menor quantidade (BELO HORIZONTE, 1953). Essa mudança parece indicar a preocupação da Biblioteca com o público em geral, aumentando a possibilidade

\footnotetext{
${ }^{3}$ Não se sabe até 0 momento o exato significado daquelas numerações: $1^{\underline{a}}, 2^{a}$, $3^{\underline{a}}$ e $4^{a}$. Mas subtende-se que tenha elas tivessem relação com uma hierarquia, em que o funcionário de $1^{\underline{a}}$ estivesse em um nível superior que o de $2^{\mathrm{a}}$, e assim sucessivamente.
} 
de consulta na instituição por um número maior de pessoas. Entretanto, a Biblioteca iniciou o seu declínio, uma vez que o acervo começou a ser considerado cada vez mais precário por seus usuários.

Não foi encontrado registro que mencionasse mudança significativa sobre a preservação, exceto informações sobre capeamento com material plástico e encadernação das obras mais estragadas, feitas por especialistas.

Como herança do Estado Novo, o campo literário em todo o país ficou sob a tutela do Estado Brasileiro. Uma das instituições criadas foi o Instituto Nacional do Livro, em 1937, que tinha por objetivo incentivar a organização e auxiliar a manutenção de bibliotecas públicas em todo o Brasil. No entanto, sua atuação social se construiu basicamente a partir da questão do livro: editoração, distribuição, venda e controle. Por essa razão, as bibliotecas públicas ficaram em segundo plano na nova política cultural. Em 1946, foi criada uma nova constituição, de caráter liberal-democrático, que definiu o Brasil como uma República federativa e estabeleceu as competências da União, Estados e Municípios. Já no início da década de 1960, o Brasil passou por um período de agitações políticas já que naquele momento o Presidente João Goulart, ao tentar implantar uma reforma agrária, enfrentou oposições políticas, situação que contribuiu para a gestação do golpe militar de 1964. Encerrou-se assim o curto período democrático no Brasil, dando lugar a um regime autoritário e repressor. Os presidentes militares reinauguraram aquele instituto, mas a atuação dessa instituição continuou a mesma da ditadura varguista. Em Belo Horizonte, o momento político também se complicava. Jorge Carone foi afastado da Prefeitura em 1965, atingido pela onda de cassações e perseguições que se seguiu ao golpe.

Foram encontrados poucos registros sobre a atuação da Biblioteca, a partir da década de 1940. O acervo foi se tornando cada vez mais apropriado para estudantes do nível primário, em detrimento dos estudantes do nível superior, provavelmente porque o primeiro grupo concentraria a maior parte dos usuários da instituição. Os assuntos passaram a se concentrar em literatura infantil, história, geografia, biografia, ciências sociais, direito, filosofia, teologia, religião, artes, ciências puras e aplicadas, por serem mais voltados para aquele tipo de público. Ao mesmo tempo, a Prefeitura estava reformando e ampliando seus serviços, por meio do decreto no 209, publicado em 1947, que criou vários departamentos, dentre eles, o Departamento de Educação e Cultura, ao qual a Biblioteca tornou-se subordinada (BELO HORIZONTE, 1992-1994d). Esse decreto, através do artigo 115, também determinou que a instituição deveria cooperar com o Serviço de Turismo e Recreação, também subordinado àquele departamento, no preparo da parte relativa às exposições de livros, das quais a Biblioteca deveria participar e que integrariam o programa de atividades turísticas. Com isso, a Biblioteca adquiriu uma competência até então inexistente para ela, que era trabalhar no apoio ao turismo, em parceria com outro setor da Prefeitura. Diante dessa alteração, no entanto, podemos novamente perceber que ela perdeu a sua autonomia no espaço administrativo da Prefeitura.

Nessa fase, começou a haver uma preocupação por parte da Biblioteca Pública de Belo Horizonte em proporcionar maior acesso à informação de seu acervo, o que podemos notar na Lei Municipal no 333 de 23 de maio de 1953, ao determinar que uma das competências da instituição seria a efetivação de 
campanhas educativas visando estimular o gosto pela leitura e incentivar a freqüência de leitores à Biblioteca e manter articulação permanente com os funcionários da Administração do Departamento de Educação e Cultura, para solução dos problemas administrativos que não lhe eram pertinentes (BELO HORIZONTE, 2004). Essa última competência reforçava a dependência que a Biblioteca mantinha em relação àquele departamento. Por outro lado, aquela lei nos mostra que surgiu uma consciência, por parte da Administração Municipal, de que a instituição deveria contribuir para o progresso social da cidade, como comprova o relatório a seguir:

Para atender às exigências do progresso social devem ser
incrementadas ao máximo as atividades que visem ao
aprimoramento do senso artístico, cultural e recreativo da
população. As bibliotecas de Belo Horizonte concorrem, com seu
acervo bibliográfico à disposição dos consulentes, para se atingir
àquele fim... (BELO HORIZONTE, 1956, p. 24)

A Biblioteca permaneceu subordinada ao Departamento de Educação e Cultura, condição que permaneceu até a transferência do acervo para o Instituto Municipal de Administração e Ciências Contábeis, em 1963.

\section{A EXTINÇÃO}

Dois fatores podem ser considerados os motivos principais da extinção da Biblioteca Pública de Belo Horizonte.

O primeiro fator se trata da Câmara dos Vereadores, antigo Conselho Deliberativo, estar necessitando urgentemente de um maior espaço para que os vereadores pudessem fazer suas deliberações. A Biblioteca Pública de Belo Horizonte, naquele momento, ocupava esse espaço. Os membros da Câmara aguardavam uma medida administrativa, por parte da Prefeitura de Belo Horizonte, para resolver tal problema. No entanto, a Administração não se manifestou, atitude que descontentava ainda mais aos representantes legislativos municipais.

Os cuidados necessários a uma instituição cultural da cidade não pareciam ser relevantes aos vereadores de Belo Horizonte. Então, segundo artigos da época, o presidente da Câmara, Nilson Gontijo, em 3 de agosto de 1963 acabou despejando o acervo da Biblioteca nos bancos do Parque Municipal. Essa atitude, obviamente, provocou um forte sentimento de indignação por parte do público de Belo Horizonte, e que foi expresso em vários artigos de jornais.

É inegável a importância que a Biblioteca tinha para Belo Horizonte e sua remoção do edifício foi bastante prejudicial para a população da cidade. $O$ acervo era ainda consultado por um público variado e possuía um valor cultural considerado pelos usuários. No entanto, as reclamações não foram suficientes e a ação do vereador Nilson Gontijo foi concretizada.

O segundo fator foi denominado aqui como uma "morte construída". O primeiro passo para o desenvolvimento do acervo da Biblioteca Estadual foi a organização da seção "Biblioteca dos Autores Mineiros", determinada pelo decreto no 64, em 1930 (BELO HORIZONTE, 1992-1994c), e pelo decreto no 67, 
em 1936 (BELO HORIZONTE, 2004). A seção deveria compreender livros sobre história e a geografia de Minas Gerais, além de obras literárias de autores mineiros e outros documentos relativos ao estado.

No ano de 1953, o governador de Minas Gerais deu os primeiros passos para a construção da Biblioteca Estadual, cujo primeiro diretor e organizador foi o escritor Eduardo Frieiro.

Em 1954, a Lei Estadual o 1087, de 2 de junho criou, enfim, a Biblioteca Pública de Minas Gerais (MINAS GERAIS, 2004). Em contrapartida, a Biblioteca Pública de Belo Horizonte, nesse período até a década de 1960, foi perdendo o apoio da Prefeitura e, gradativamente, com a redução do atendimento ao público, também perdeu o prestígio na cidade, até finalmente ser extinta em 1963.

A extinção da Biblioteca Pública de Belo Horizonte se deu, em termos legislativos, em 1963, pela publicação da Lei Municipal $n^{\circ} 1054$, de 7 de novembro, que determinou a transferência do acervo da instituição para o Instituto Municipal de Administração e Ciências Contábeis (BELO HORIZONTE, 1965).

Em termos administrativos, a instituição ainda não havia sido extinta; no entanto, sua atuação como biblioteca pública municipal foi praticamente anulada em seu novo local. Por isso podemos dizer que, apesar dos protestos da comunidade, a cidade de Belo Horizonte perdeu a sua biblioteca pública, fato descrito com pesar no seguinte artigo, escrito por Frieiro ${ }^{4}$ :

No ano de 1963 foi a Biblioteca despejada do local em que se achava, sendo levada para uma das salas do edifício do IMACO, no Parque Municipal. Não era grande. Tinha aproximadamente 20.000 volumes. Mas os serviços que prestou à educação do povo, durante 68 anos de frequentação pública, foram realmente inestimáveis. Não podem ser esquecidos (1970, p. 53).

Essa transferência gerou inúmeras perdas no acervo, sendo que muitas foram irreversíveis: parte dele se perdeu e outra parte foi, em determinado momento, desmembrada e transferida para o Instituto João Pinheiro. Esse processo provocou a fragmentação das coleções constituídas pela Biblioteca Pública de Belo Horizonte ao longo de sua trajetória; dessa forma, a instituição, ao perder o seu acervo, acabou sendo esquecida pelos habitantes da cidade.

\section{CONSIDERAÇÕES FINAIS}

Para apresentarmos a importância que a biblioteca exerceu em Belo Horizonte, devemos fazer primeiramente alguns apontamentos.

A memória, basicamente, constitui em vestígios que ligam o homem ou um grupo social ao seu passado. A biblioteca pública é uma guardiã de alguns desses vestígios, pois nela se encontram documentos escritos e audiovisuais, livros, periódicos, jornais, produzidos pela comunidade que a abrigou e que refletiram os ideais, as aspirações, os sentimentos dos membros que fazem parte do grupo.

\footnotetext{
${ }^{4} \mathrm{O}$ artigo não apresenta titulação, por esse motivo ela não será citada nas referências.
} 
A identidade de uma pessoa ou de um grupo social, por sua vez, é baseada na memória. A nossa identidade individual, essencialmente, consiste em saber quem somos, do que gostamos e o que pretendemos para o nosso futuro. Para descobrirmos essas respostas, recorremos a nossa memória. Por outro lado, procuramos estar sempre junto de outras pessoas que compartilhem semelhantes costumes, tais como o estudo, o lazer e as formas de expressão; até chegar a um grupo maior, que compõe uma nação e apresenta hábitos culturais semelhantes, como a língua, as músicas e danças, religiões, a organização política, dentre outros. A identidade cultural - seja ela local, nacional ou até mesmo global - para se preservar, precisa da memória dos membros componentes, expressada na linguagem, nas expressões artísticas, nas celebrações, na literatura (dentre outras manifestações) e nos documentos acumulados.

Assim, podemos concluir que a Biblioteca Pública de Belo Horizonte contribuiu para a constituição da memória e identidade da cidade, tendo em vista: o acervo doado por figuras ilustres da cidade, dentre eles, os membros da Comissão Construtora da Nova Capital; os periódicos e jornais publicados na cidade e recebidos pela Biblioteca; o desenvolvimento e organização da seção "Autores Mineiros"; a publicação do "Boletim Bibliographico"; a frequência de escritores e intelectuais à Biblioteca, bem como sua produção literária e científica; os trabalhos, as pesquisas e as leituras realizados por estudantes e pela população em geral; os hábitos de leitura e escrita criados na Biblioteca e por essa instituição; as influências ideológicas que atingiram a Biblioteca e, indiretamente os seus usuários; as influências culturais que modificaram ou foram modificadas pela leitura e pela escrita na instituição.

A Biblioteca Pública de Belo Horizonte, apesar de ter apresentado sérios problemas e de ter sido influenciada pela história da cidade e do país, influenciou também a trajetória histórica de Belo Horizonte, bem como fez parte dela. Nesse sentido, a cidade sofreu com a extinção dessa instituição, perdendo assim parte de sua história. O acervo da Biblioteca, sendo desmembrado e distribuído em outros locais, deixou de ser especificamente "acervo da Biblioteca Pública de Belo Horizonte", para ser apenas parte de coleções de outras instituições. Sendo assim, o acervo perdeu sua própria identidade.

\section{REFERÊNCIAS}

BARRETO, Abílio. "Texto sobre a fundação da Biblioteca Pública pelos funcionários da Comissão Construtora e sua trajetória: 1894-1932". [S.I.: s.n.; 19-]. $5 p$.

BEISIEGEL, Celso de Rui. Educação e sociedade no Brasil após 1930. In: FAUSTO, Boris (Dir.). O Brasil Republicano: economia e cultura (1930-1964). Rio de Janeiro: Bertrand Brasil, 1997. p. 381-416.

BELLO HORIZONTE. Relatorio apresentado ao Conselho Deliberativo pelo prefeito Dr. Bernardo Pinto Monteiro. Bello Horizonte: Imprensa Official do Estado de Minas Geraes, 1902. 273 p. 
- Relatorio apresentado ao Conselho Deliberativo pelo prefeito Francisco Bressane de Azevedo. Bello Horizonte: Imprensa Official do Estado de Minas, 1903. $191 \mathrm{p}$.

- Relatorio apresentado ao Conselho Deliberativo da Cidade de Bello Horizonte pelo prefeito Francisco Bressane de Azevedo em setembro de 1905. Bello Horizonte: Imprensa Official de Minas Geraes, 1906. 205 p.

Relatorio apresentado ao Conselho Deliberativo pelo prefeito Flavio Fernandes dos Santos. Bello Horizonte: Imprensa Official do Estado de Minas Geraes, 1923. $171 \mathrm{p}$.

BELO HORIZONTE. Decreto $\mathrm{n}^{\circ} 16$, de 12 de maio de 1927. Regulamenta os serviços da Prefeitura. Legislação de Belo Horizonte 1891 a 1996: leis, decretos, portarias e resoluções. Belo Horizonte: PRODABEL, 1992-1994a. 1 CD-ROM

. Decreto $n^{\circ} 63$, de 06 de março de 1930. Abre um crédito especial de 704:956\$000 para pagamento de despesas imprevistas. Legislação de Belo Horizonte 1891 a 1996: leis, decretos, portarias e resoluções. Belo Horizonte: PRODABEL, 1992-1994b. 1CD-ROM

Decreto $n^{\circ} 64$, de 07 de março de 1930. Regulamenta a Biblioteca de Belo Horizonte. Legislação de Belo Horizonte 1891 a 1996: leis, decretos, portarias e resoluções. Belo Horizonte: PRODABEL, 1992-1994c. 1 CD-ROM.

. Decreto $n^{\circ} 67$, de 11 de fevereiro de 1936. Dá novo regulamento á Bibliotheca Publica de Bello Horizonte. Disponível em: <http://bhz5.pbh.gov.br/legislação.nsf> Acesso em: 30 jan. 2004.

Decreto ํo 135 de 21 de outubro de 1937. Determina a verificação dos livros existentes na Biblioteca Pública. Decretos e Resoluções de 1937. Belo Horizonte: Prefeitura, p. 45 - 46, 1938.

. Decreto $n^{\circ} 209$, de 11 de novembro de 1947. Organiza os serviços da Prefeitura de Belo Horizonte. Legislação de Belo Horizonte 1891 a 1996: leis, decretos, portarias e resoluções. Belo Horizonte: PRODABEL, 1992-1994d. 1 CD$\mathrm{ROM}$

Lei $\mathrm{n}^{0}$ 333, de 23 de maio de 1953. Dispõe sobre a organização administrativa da Prefeitura de Belo Horizonte, e dá outras providências. 1955. Disponível em: <http://bhz5.pbh.gov.br/legislação.nsf> Acesso em: 30 jan. 2004.

. Lei no 1.054, de 7 de novembro de 1963. Amplia, reestrutura e incorpora a Biblioteca Pública ao IMACO e contém outras providências. Legislação Municipal de 1963. Belo Horizonte: Departamento de Administração, p. 62-63, 1965.

Relatório de 1952 apresentado à Câmara Municipal pelo Prefeito Américo Renê Giannetti. Belo Horizonte: Prefeitura de Belo Horizonte, 1953. 252 p. 
Relatório de 1955 apresentado à Camara Municipal pelo Prefeito Celso Mello de Azevedo. Belo Horizonte: Prefeitura de Belo Horizonte, 1956. 35 p.

BOLETIM Bibliographico, Bello Horizonte, anno I, set./out. 1935. 2v.

BRASIL. Lei $n^{\circ} 38$, de 04 de abril de 1935. Define crimes contra a ordem política e social. Disponível em:<wwwt.senado.gov.br/netacgi/nph-brs.exe> Acesso em: 17 ago. 2004.

FRIEIRO, Eduardo. In: Boletim da Biblioteca Pública de Minas Gerais "Prof. Luis de Bessa", Belo Horizonte, v. 1, jul. 1970.

MENEGALE, J. Guimarães. O que é e o que deve ser a Biblioteca Pública. Belo Horizonte: Imprensa Oficial, 1932. $104 \mathrm{p}$.

MINAS GERAIS. Lei n ${ }^{\circ}$ 1.087, de 02 de junho de 1954. Cria a Biblioteca Publica de Minas Gerais e da outras providências. Disponível em: <http://hera.almg.gov.br/cgi-bin/nph-brs> Acesso em: 17 ago. 2004.

MOTTA, Rodrigo Patto Sá. O diabo nas bibliotecas comunistas: repressão e censura no Brasil dos anos 1930. In: POLÍTICA, nação e edição: Brasil, Europa e Américas nos séculos XVIII-XX. Belo Horizonte: Editora UFMG: 2003. 119 p.

\title{
Title
}

The Public Library of Belo Horizonte: the cultural legacy of a literary society

\begin{abstract}
This paper presents the historical reconstruction of the public library of Belo Horizonte, from its founding to its extinction. It analyzes the library contribution for the knowledge heritage, cultural legacy and identity of the city. The theoretical framework was based on studies about public libraries and the history of Belo Horizonte, Brazil. The methodological approach involved the document analysis technique, supplemented by theoretical sources. The set of documents included both official documents, such as public reports and legislation, and non-official sources, such as newspapers and articles. The combination of both types of source allowed a dialectical approach. The history of the library was divided into three different stages: foundation, institutionalization and extinction. The public library of Belo Horizonte proved to be a major contributor for the knowledge heritage and cultural legacy and identity of the city, in respect to its collection and services.
\end{abstract}

\section{Keywords}

Public Libraries. Cultural Identity. Knowledge Heritage.

\section{Titulo}

La biblioteca pública de Belo Horizonte: el legado cultural de una sociedad literaria 


\section{Resumen}

Se presenta la reconstrucción histórica de la Biblioteca Pública de Belo Horizonte, desde su fundación hasta su extinción. Analiza la contribución de la Biblioteca para la formación de la memoria y de la identidad de la ciudad. El marco teórico se basa en estudios de la biblioteca pública y en lecturas sobre la historia de Belo Horizonte y del Brasil. La metodología tiene como eje el análisis documental, complementado mediante la consulta de las fuentes teóricas. Los documentos examinados son de origen oficial, tales como los informes y la legislación, y fuentes no oficiales, tales como artículos de prensa. La contraposición documental ha permitido un enfoque dialéctico. La historia de la biblioteca se divide en tres etapas: creación, institucionalización y extinción de la institución. La contribución de la Biblioteca Pública de Belo Horizonte para la formación de la memoria y de la identidad de la ciudad se confirmó por medio de la colección y de los servicios ofrecidos por la institución.

\section{Palavras clave}

Bibliotecas públicas. Identidad cultural. Memoria

Recebido em: 11/06/2010

Aceito em: 11/02/2011 